\title{
Tribological evaluation of duplex treatment of plasma nitriding/ oxidation applied to injection mold extraction system
}

\author{
Tiago Marcelo Reis ${ }^{1,2}$ \\ Aline Luisa Bandeira Dotta ${ }^{2}$ \\ Maria Cristina Moré Farias ${ }^{2}$ \\ Alexandre Luís Gasparin ${ }^{1 *}$
}

\begin{abstract}
This work analyzes the application of surface treatment of plasma nitriding with post-oxidation applied to injection mold extractor pins to reduce the injection cycle's interruptions for mold lubrication. For that, a device that simulates the operation of the injection mold extraction system was created. Wear was evaluated by mass loss and dimensional variation of the extraction pins and their bushings. The samples were characterized by microhardness and X-ray diffraction (XRD). The wear mechanisms were identified by scanning electron microscopy (SEM) and the coefficient of friction was analyzed employing a ball-on-plate tribological test. The results showed that the proposed system with plasma nitriding and postoxidation meets the requirements with a lubrication interval twice as long as the current system.
\end{abstract}

Keywords: Injection mold; Plasma nitriding; Post-oxidation; Tribology.

\section{Introduction}

Sliding systems, such as the extraction mold components, are susceptible to premature wear, if not well lubricated. The productivity can be improved by reducing the number of maintenance interruptions due to the extraction system lubrication. Such a system is composed of pins and bushes, which are the focus of this work. Once the lubrication is a common practice to avoid extraction system premature wear $[1,2]$.

Thermoplastic injection molds have metal parts with relative movements that require the use of lubricants to ensure sliding and to prevent premature wear. It is necessary, however, to replace the lubricant at certain operating intervals, which increases the time of the production cycle [1]. Thus, the search for other solutions than periodic lubrication by fluids becomes necessary to eliminate or even to increase the intervals of lubrication.

Plasma nitriding gives to steel a raise in wear resistance $[3,4]$, while post-oxidation tends to reduce the coefficient of friction when compared to steel without treatment [5]. Those characteristics make this study interesting for the application in injection mold extractor pins to increase the intervals between lubrications.

Considering the main types of extractor used industrially, the most used is the cylindrical extractor pin. According to DIN 1530 [6], they can be of two types: A or B. Type A is manufactured in AISI H13 steel, core hardness of approximately
$40 \mathrm{HRc}$, gas nitrided with surface hardness between 65 and $70 \mathrm{HRc}$ and with rectified surface finish $(\mathrm{Rz}=2.5 \mu \mathrm{m})$. Type B pin is manufactured in AISI WS steel, body with total quenching, and hardness between 60 and $62 \mathrm{HRc}$. Type $\mathrm{B}$ has the same surface finish as type A [1,2]. There is also another type of extractor pin that is not standardized, which is manufactured in stainless steel with sub-zero heat treatment. This type of pin was patented by Kozaburo [7] and is applied for the injection of corrosive materials.

The nitriding in ferrous materials can produce two different structures, depending on the parameters or process used. The first one is the formation of a layer with nitrogen diffused into the metal forming dispersed nitrides of alloying elements, the so-called "diffusion zone". The other structure is composed of the diffusion zone and a surface layer of nitrides such as $\mathrm{Fe}_{2} \mathrm{~N}, \mathrm{Fe}_{3} \mathrm{~N}$ and $\mathrm{Fe}_{4} \mathrm{~N}$ called the composite layer and also known as the white layer [8,9].

The post-oxidation is a thermochemical treatment complementary to the nitriding. In that treatment, the incorporation of oxygen to the surface of the material occurs forming a layer composed of iron oxides. These oxides can be magnetite $\left(\mathrm{Fe}_{3} \mathrm{O}_{4}\right)$ or hematite $\left(\mathrm{Fe}_{2} \mathrm{O}_{3}\right)$. The plasma postoxidation process offers to the material a reduction in the friction coefficient, an increase in the corrosion resistance, and a higher chemical stability when compared just to the nitrided steel [5,10-12].

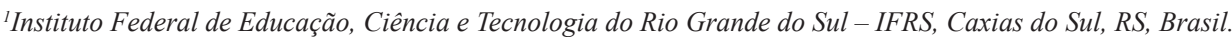

${ }^{2}$ Centro de Ciências Exatas e Tecnologia, Universidade de Caxias do Sul-UCS, Caxias do Sul, RS, Brasil.

*Autor correspondente: alexandre.gasparin@caxias.ifrs.edu.br 
According to the data found by Alsaran et al. [5], it's possible to observe that the layer with a higher amount of magnetite presents better tribological properties. Menezes et al. [10] and Freislebem et al. [13] observed a reduction of the nanoscale friction coefficient of nitrided samples when post-oxidized, which was related to the vibrational damping of the surface chemical species.

Wear can be described as the damage (removal of material) imposed on a solid body surface caused by the mechanical action of a solid, a liquid, or a gas. In systems involving metal pairs under sliding, the wear mechanisms can be characterized in four ways: adhesive, abrasive, fatigue, and corrosive wear [14].

In abrasive wear, the wear particles (debris) play an important role in the wear mechanism [15]. The main characteristics of the wear particles that affect the wear rate are size, hardness, shape, and fracture toughness [16]. The magnitude of the abrasive wear can be estimated considering the ratio between the abrasive particle hardness and the hardness of worn material [17].

This work aims to evaluate the surface treatment of nitriding to plasma with post oxidation, as an alternative to replace the system currently used in industry, with gas nitrided pins only, aiming to reduce the amount of their lubrication intervals.

\section{Materials and methodology}

The bushings were manufactured using quenched and tempered steel AISI H13 by machining and its internal diameter by wire electroerosion cut. The bushings hardness obtained was $50 \mathrm{HRc}$ and the tolerance adjustment $\mathrm{H} 7$. The bushings' designations were "BN" for gas nitrided and "BO" for plasma nitrided and post-oxidized.

The extractors pins selected for this work were the type A, with a diameter of $5 \mathrm{~mm}$, a tolerance adjustment of g6, and a length of $125 \mathrm{~mm}$, according to standard DIN 1530/2011 [6]. These were commercial pins, manufactured by the Sulmax company, (product code: PEA05.0125), in AISI H13 steel, quenched and tempered (40 HRc of core hardness) and gas nitrided (1025 HV of nitrided layer hardness). The extractors' pins designations were "PN" for gas nitrided and "PO" for plasma nitrided and post-oxidized. The plasma nitriding and post-oxidation layer treatment were carried out by Plasmar Company, the process parameters are shown in Table 1.

A device to simulate the extraction system of an injection mold was created to the wear test, according to Figure 1. The pins were attached to the movable plate, while the bushes were attached to the fixed plate.

The movable plate and the pins cycled at a $0.19 \mathrm{~m} / \mathrm{s}$ speed at a temperature between 15 and $25^{\circ} \mathrm{C}$. The lubrication executed applying a commercial paraffin-based grease with lithium soap, Wurth brand. The grease was manually applied to the extractor pins, covering the sliding area. The number
Table 1. Process parameters used for plasma nitriding and postoxidation of the samples

\begin{tabular}{lcc}
\hline \multicolumn{1}{c}{ Parameters } & Nitrided value & Oxidation value \\
\hline Base Pressure $(\mathrm{Pa})$ & 5 & 0.05 \\
Work pressure $(\mathrm{kPa})$ & 0.4 & 1 \\
Nitriding time $(\mathrm{h})$ & 12 & 90 \\
Temperature $\left({ }^{\circ} \mathrm{C}\right)$ & 480 & 480 \\
Proportion of gases $(\%)$ & $\mathrm{N}_{2} 20 \%-\mathrm{H}_{2} 80 \%$ & $\mathrm{Ar} 25 \%-\mathrm{CO}_{2} 75 \%$ \\
Current $(\mathrm{A})$ & 6 & 5 \\
Frequency $(\mathrm{kHz})$ & 5 & 5 \\
Duration of pulse $(\%)$ & 30 & 30 \\
\hline
\end{tabular}

of cycles to lubricate the pins was defined as 50,000 cycles, giving a total distance of $5,000 \mathrm{~m}$ for the gas-nitrided pins. However, for the post-oxidation plasma nitrided pins, the lubricating interval was defined as 100,000 cycles or a total distance of $10,000 \mathrm{~m}$. Such considerations aimed to test the proposed system (PO-BO).

The mass variation was checked at each lubrication interval (50,000 and 100,000 cycles), in a Bel Engineering analytical balance.

The dimensional checking of the pair (pin/bush) was done every 200,000 cycles for both systems, subtracting the internal measurement of the bushing holes from the external diameter of the pins. The measures executed in a three-dimensional CNC, a Mitutoyo Beyond Crysta model, had a resolution of $0.0001 \mathrm{~mm}$.

The microhardness profiles were measured from the surface to the core of the pin cross-section through a microdurometer, Pantec model: MV2000A. The measurements were executed on the Vickers scale and according to ASTM E92/2016 [18]. A load of $25 \mathrm{~g}$ applied for $15 \mathrm{~s}$ was used to the three measurements at each surface depth.

The XRD technique to identify the crystalline phases in the layers of the gas nitrided and plasma nitrided with post-oxidation pins used a diffractometer model XRD-6000 from Shimadzu manufacturer. The analysis had the following settings: $\mathrm{Cu} \mathrm{K} \alpha$ radiation with $0.154184 \mathrm{~nm}$ wavelength, an acceleration voltage and current of $40 \mathrm{kV}$ and $30 \mathrm{~mA}$, respectively, an angle range of $30^{\circ}$ to $90^{\circ}$, scan speed $0.02 \%$ and a $2^{\circ}$ of razor angle. For the gas nitrided sample characterization, a pin was cut with a $30 \mathrm{~mm}$ length and cleaned with PA acetone. A cube of $20 \mathrm{~mm}$ edge of AISI H13 material was plasma-nitrided and post-oxidized together to the pins to the X-ray diffraction perform on a treated cube face.

The SEM analysis used an equipment model Tescan 3. The sample preparation: the bushings were cut in the middle of the longitudinal section, while the pins samples were cut $20 \mathrm{~mm}$ from the head (region without wear) and 70 and $80 \mathrm{~mm}$ from the pinhead (wear region).

The friction coefficients of the plasma nitrided with post-oxidized surface samples and the plasma nitrided without post-oxidation samples were measured through the ballon-plate test in the linear oscillatory mode. An equipment Bruker model UMT Tribolab was used with the following 


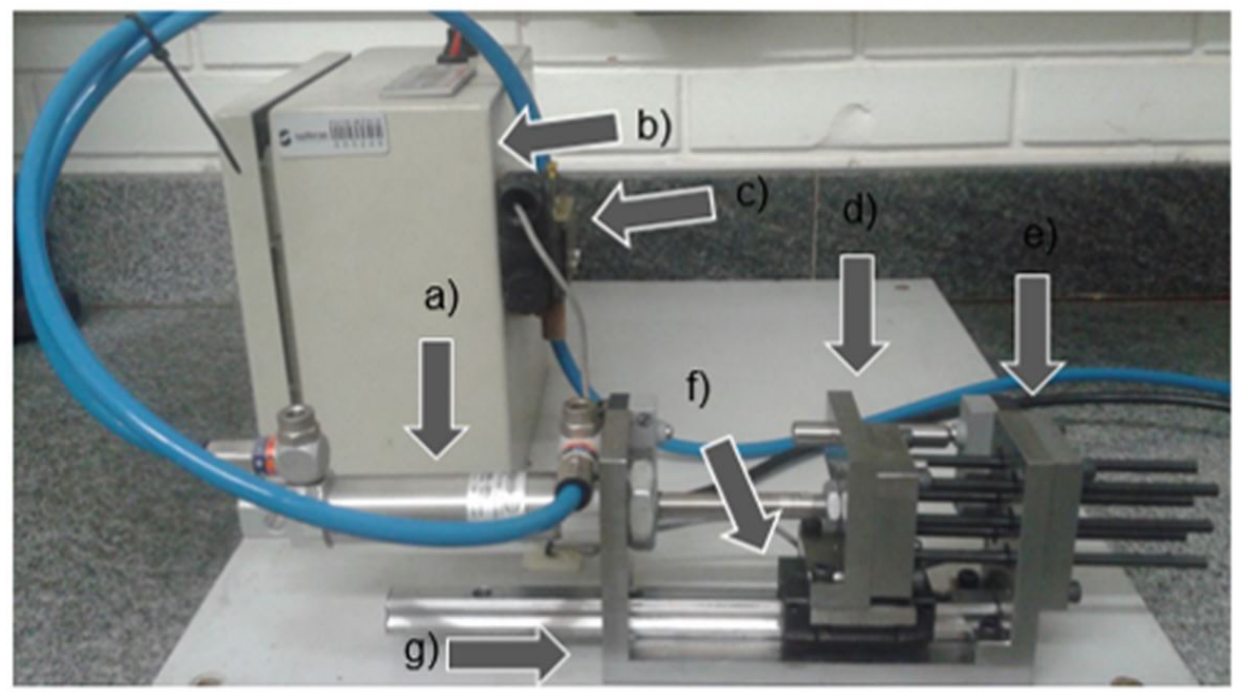

Legend:

a) Pneumatic cylinder

b) Control panel

c) Pneumatic valve

d) Movable plate

e) Fixed plate

f) Linear guide system

g) Fixing base

Figure 1. Apparatus for simulation of wear in injection mold extraction system.

parameters: load $(3 \mathrm{~N})$, frequency $(11,875 \mathrm{~Hz})$, linear velocity $(0.19 \mathrm{~m} / \mathrm{s})$, track time $(1.5 \mathrm{~h})$, track length $(8 \mathrm{~mm})$ and a total displacement of $1,026 \mathrm{~m}$. Three tracks were done for each sample. The counter body used was an alumina sphere of $6 \mathrm{~mm}$ in diameter.

\section{Results and discussions}

The wear rates in the post-oxidized system were higher in the pins than in the respective tempered bushings. Nevertheless, the gas nitrided pins without post-oxidation presented lower weight loss than the respective tempered bushings, (see Figure 2). The post-oxidized pins presented the higher weight loss, followed by the nitrided bushings, nitrided pins, and the lower weight loss, the post-oxidized bushing. At 800,000 cycles, the pins (PO) presented $0.0103 \mathrm{mg} / \mathrm{mm}^{2}$ of mass loss, while the (PN) had only $0.0068 \mathrm{mg} / \mathrm{mm}^{2}$. The bushings (BO) system with a lubrication interval of 100,000 cycles presented a lower wear than the gas nitride system bushings (BN) with lubrication intervals of 50,000 cycles. With 800,000 cycles, the (BO) presented $0.0061 \mathrm{mg} / \mathrm{mm}^{2}$, while BN showed $0.0103 \mathrm{mg} / \mathrm{mm}^{2}$ of weight loss. Although there were particles of the iron oxide layer during the wear test, the post-oxidized bushing presented the highest wear resistance or lower weight loss.

The post-oxidized pins with a lubrication interval of 100,000 cycles exhibited a higher wear than gas nitrided pins with a lubrication interval of 50,000 cycles. Such results were significant to the improvement of the decreasing of the lubricating intervals.

The clearance between pins and bushings during the cycling device test was obtained as specified in the design, g6 / H7, according to the norm ISO 286-1/2010 [19]. For the $5 \mathrm{~mm}$ shaft/bore system, the minimum and maximum tolerances are 4 and $24 \mu \mathrm{m}$, respectively (see Figure 3).

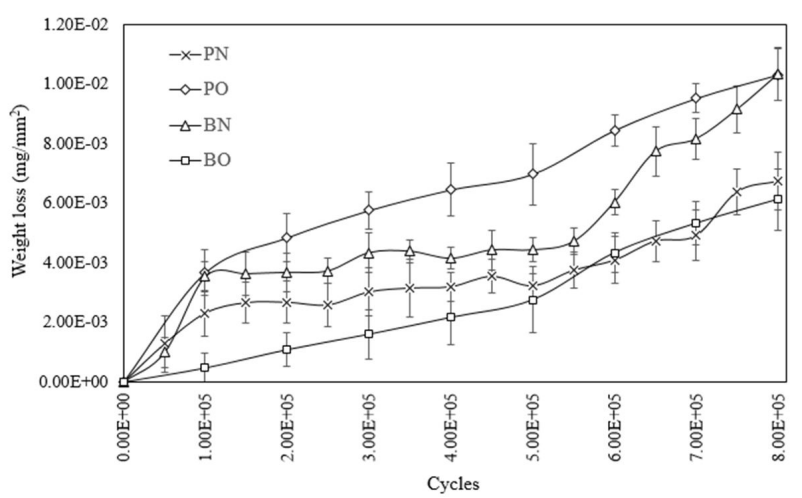

Figure 2. Wear rate of pins and bushings per unit of contact area.

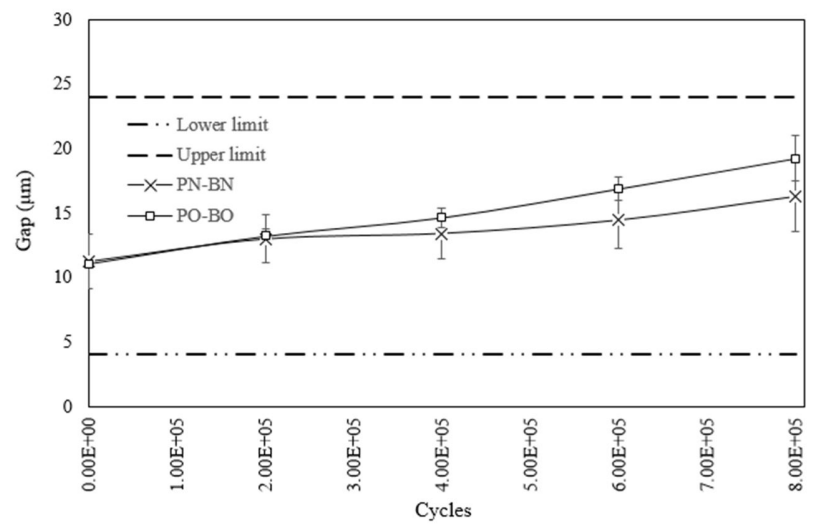

Figure 3. Dimensional variation of the clearance between pins and bushings.

The clearances for both systems PO-BO and PN-BN (Figure 3) after running the bench test (Figure 1) were kept in conformity to the tolerances specified in the design specifications. The system with oxidized pins presented a larger clearance from 200,000 cycles to 800,000 cycles, although the results remained inside the lower and upper design limits, see results in Figure 3.

As observed in Figure 4, the microhardness profile to the nitrided pins presented the highest hardness close to 


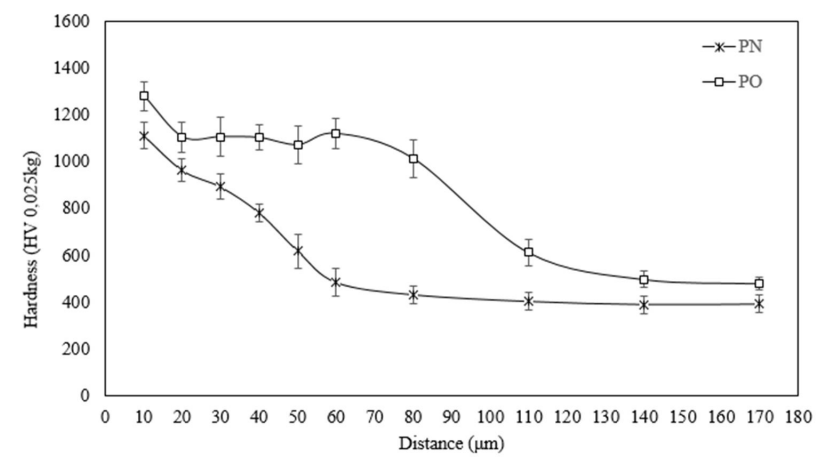

Figure 4. Microhardness of gas nitrided and plasma nitrided with post-oxidation.

the pin surface. Such results were expected, once the surface received a great number of nitrides, during the plasma $(\mathrm{PO})$ or gas nitriding pins $(\mathrm{PN})$. While the PO presented the highest hardness all over the profile. The indenter penetrated the post oxidized layer, reaching the plasma nitrided layer.

Gas nitrided pins presented the highest hardness in a penetration of approximately $40 \mu \mathrm{m}$ depth from the surface, while for plasma nitrided and post-oxidized pins the penetration thickness was approximately $80 \mu \mathrm{m}$. Those values verified that the layer hardness reached a hardness $50 \%$ higher than the core. The plasma nitriding process is based on the acceleration of nitrogen ions into the target surface, while the gas nitriding process, on the nitrogen diffusion through the surface by heating and due to the ammonia gas concentration.

Figure 5 shows the diffractogram of the gas nitrided pin surface layer and the post-oxidized plasma nitrided pin. According to the diffractogram, the presence of the phases $\varepsilon-\mathrm{Fe}_{2-3} \mathrm{~N}$ (hexagonal compact) and $\gamma^{\prime}-\mathrm{Fe}_{4} \mathrm{~N}$ (face-centered cubic) was detected. When compared to the results of Karamış et al. [20], it was possible to observe the epsilon phase peaks had a higher intensity compared to the gamma phase. Thus, the formation of the composite layer in the gas nitrided pins was confirmed.

The phases peaks of the XRD patterns are matched with the following JCPDS card number: $\mathrm{Fe}_{2} \mathrm{O}_{3}$ (33-0664); $\mathrm{Fe}_{3} \mathrm{O}_{4}$ (11-0614); $\varepsilon-\mathrm{Fe}_{2-3} \mathrm{~N}(1-1236)$ and $\gamma^{\prime}-\mathrm{Fe}_{4} \mathrm{~N}(6-627)$.

In Figure 5 in the diffractogram of the post-oxidized plasma nitrided pin, the presence of the magnetite $\left(\mathrm{Fe}_{3} \mathrm{O}_{4}\right)$ phase, hematite $\left(\mathrm{Fe}_{2} \mathrm{O}_{3}\right)$ phase, $\varepsilon-\mathrm{Fe}_{2-3} \mathrm{~N}$ (hexagonal compact) and $\gamma^{\prime}-\mathrm{Fe}_{4} \mathrm{~N}$ (face-centered cubic) $[21,22]$ could be observed. The significant presence of the hematite phase, the poorest oxide phase in tribological properties was also verified [5].

Figure 6 shows the images of the gas nitrided pin surface before (a) and after (b) wear. It is also possible to observe: (a) vertical grooves resulting from the finishing grinding process of the pins and (b) the presence of horizontal grooves, which result from abrasive wear [16]. It was not visualized plastic deformations at the edges of the wear track or the presence of cracks, indicating a probable abrasive wear by micro-cutting [14].

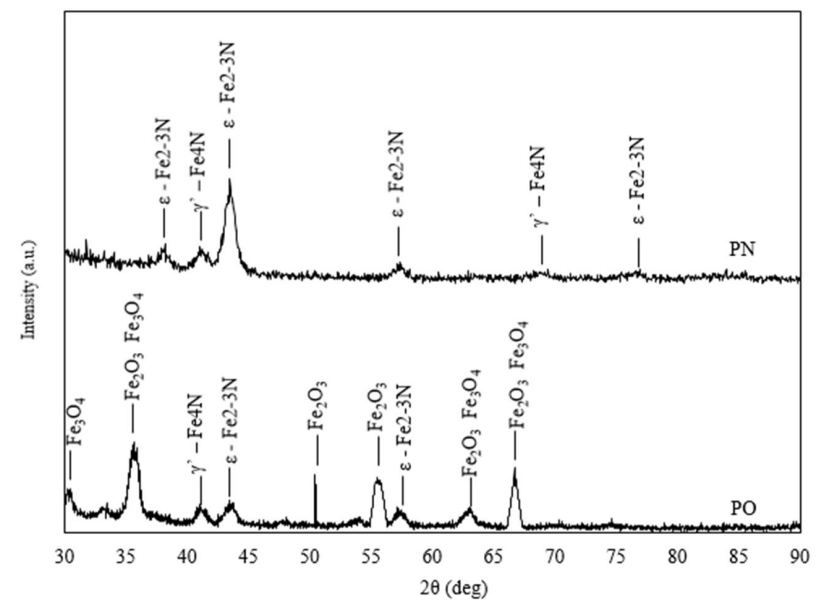

Figure 5. Diffractograms of the gas nitrided and plasma nitrided with post-oxidation.

The images of a post-oxidized plasma nitrided pin surface before and after wear are seen in Figure 7. Vertical grooves from the finishing process of the pins in Figure 7a show a defect of the post-oxidation treatment, defined as displacement or detachment [16]. Such defect indicates a poor surface adhesion between the iron oxide film and the composite layer. Figure $7 \mathrm{~b}$ shows the failures of the post-oxidized layer, the iron oxide film, leading the wear mechanism as abrasive wear by micro-cracking [16]. The plasma nitrided layer remained intact, after the bench test (wear test).

Figure 8 showed the image of a bushing surface before the wear test (a), the BN after wear test, and (b) and the BO after wear test (c). In Figure 8a was possible to verify the presence of a topography characteristic of the electroerosion process [1] on the internal surface of the bushings. In (b) and (c) figures, the main wear mechanisms in the bushings for both systems was identified as abrasive wear by microcutting, through the observation of the grooves or wear tracks in the direction of the movement of the extractor pins [16].

The bushings BN presented a smoother surface than $\mathrm{BO}$, after bench test (see Figure 8), although the $\mathrm{BO}$ weight loss was lower than the $\mathrm{BN}$ (see Figure 2). The clearance in the PN-BN system was lower than the PO-BO system (see Figure 3), due to the plasma nitriding hardness, as seen in Figure 4 . The post oxidation had more effectiveness than just the gas nitriding treatment in these tribological systems. Considering the hardness ratio of the debris particles and the substrate, as observed by Kruschov [17], who verified: as higher values for this ratio, higher the substrate wear. The PO-BO system is in accordance to the Kruschov work, it promotes a lower substrate wear, once the iron oxide particles hardness between 380 and $530 \mathrm{HV}$ [5], and the nitrided layer hardness between 900 and $1140 \mathrm{HV}$ [23] has a lower hardness ratio than the PN-BN system.

Figure 9 presented the results of the ball-on-plate tribological tests, for the friction coefficient of the nitrided samples and of the plasma nitrided with post-oxidation samples, both tests had the plate pre-lubricated. 


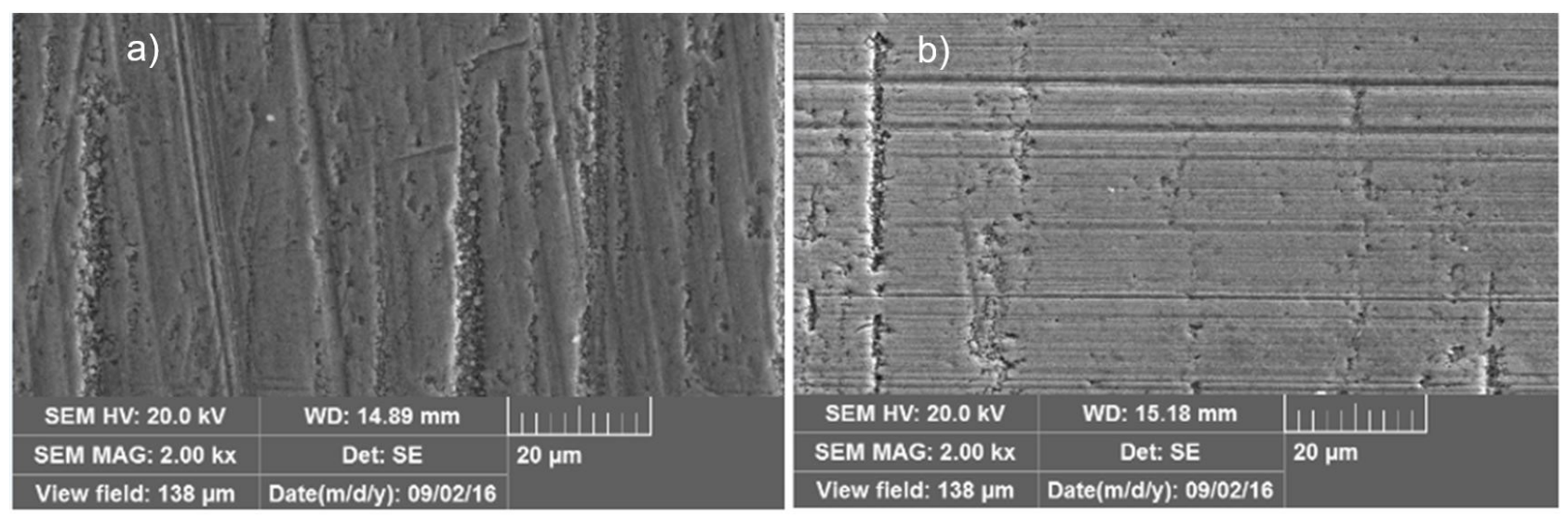

Figure 6. SEM of the surface of a gas nitrided pin, (a) before and (b) after wear.

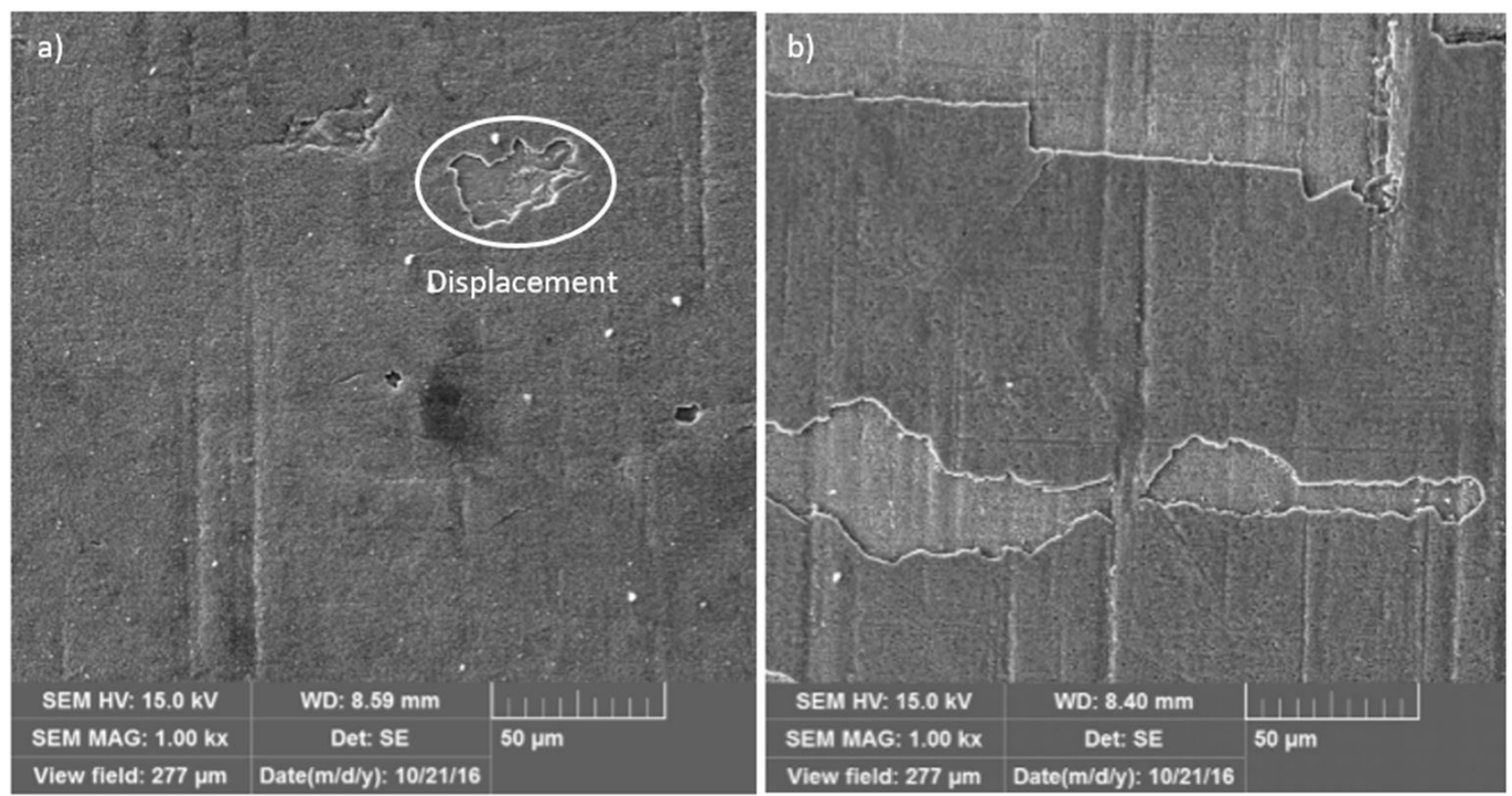

Figure 7. SEM of the surface of a post-oxidation plasma nitrided pin, (a) before and (b) after wear.
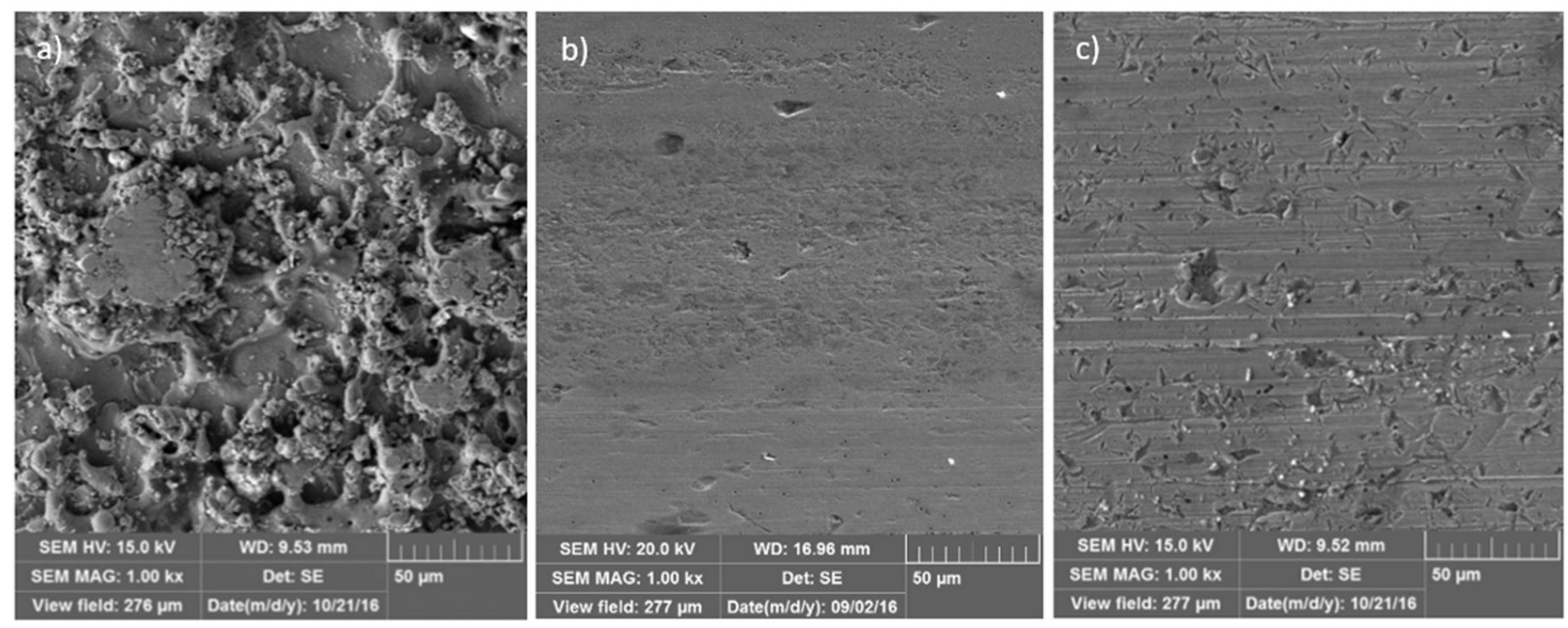

Figure 8. SEM of the internal bushing surface, (a) bushing before wear test; (b) bushing BN after wear test; and (c) bushing BO after the wear test. 


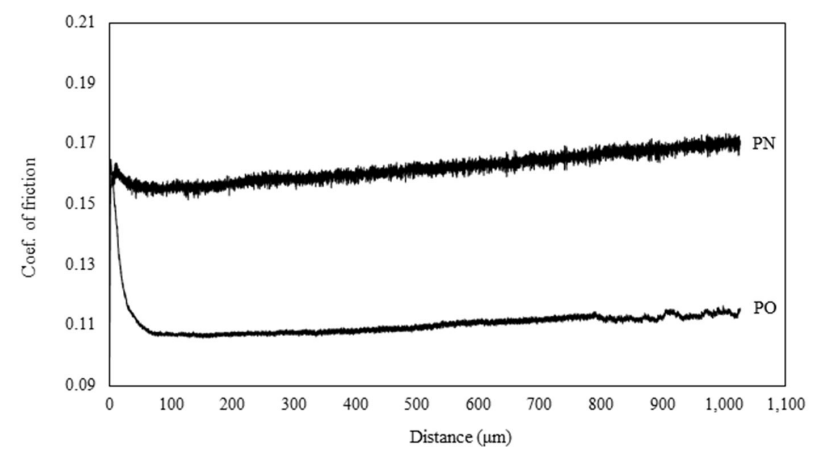

Figure 9. Coefficient of friction for plasma nitrided and plasma nitrided with post-oxidation sample.

The plasma nitrided and post-oxidized samples presented a lower coefficient of friction when compared to the only nitrided samples, considering both systems lubricated in the same way as has been done for a real mold extraction system. The coefficient of friction for the nitrided and post-oxidized samples obtained in the ball-on-plate test was 0.11 with a standard deviation of 0.005 , and the gas nitrided samples had a friction coefficient of 0.16 with a standard deviation of 0.004 . (see Figure 9). These results contributed to the choice of the proposed tribological system (PO-BO), aiming to decrease the lubrication stops in comparison to the PN-BN system.

\section{Conclusions}

According to the investigation, the system proposed with plasma-nitrided and post-oxidized pins (PO-BO), bench tested with lubrication intervals at every 100,000 cycles, presented satisfactory results concerning to the conventional system with gas nitrided pins (PN-BN) with the lubrication intervals of 50,000 cycles. The extraction $\mathrm{pin} /$ bushing system remained in conformance to the project tolerance limits after performing the bench tests, doubling the lubrication time interval.

In the current system, with gas nitrided pins, the greatest wear occurred in the bushing, not in the pins, while in the system with post-oxidized pins the opposite occurred. The replacement of pins is more suitable for injection molds, because its maintenance is simpler and cheaper than to worn bushing dismounting and its substitution.

Wear mechanisms were identified for the bushings of both systems as abrasive wear by microcutting, according to the microscopies, and the post-oxidized plasma nitrided pins showed abrasive wear due to micro-cracking.

\section{References}

1 Kazmer DO. Injection mold design engineering. Munich: Hanser; 2007.

2 Menges G, Michaeli W, Mohren P. How to make injection molds. Munich: Hanser; 2001.

3 Jisheng E, Gawne DT. Effect of thermochemical treatments on the sliding wear mechanisms of steels under boundary lubrication. Tribology Transactions. 2008;42:626-632.

4 Leite MV, Figueroa CA, Gallo SC, Rovani AC, Basso RLO, Mei PR, et al. Wear mechanisms and microstructure of pulsed plasma nitrided AISI H13 tool steel. Wear. 2010;269(5-6):466-472. http://dx.doi.org/10.1016/j. wear.2010.04.037.

5 Alsaran A, Altun H, Karakan M, Çelik A. Effect of post-oxidizing on tribological and corrosion behavior of plasma nitrided AISI 5140 steel. Surface and Coatings Technology. 2004;176(3):344-348. http://dx.doi.org/10.1016/S02578972(03)00770-9.

6 Deutsches Institut fur Normung. DIN 1530/11: tools for molding. Berlin: DIN; 2011.

7 Kozaburo U. Stainless steel ejector pin. JPS616252A. 1987.

8 Aghajani H, Behrangi S. Plasma nitriding of steels. Cham: Springer International Publishing; 2017.

9 Nayebpashaee N, Soltanieh M, Kheirandish S. A study on formation and growth mechanism of nitride layers during plasma nitriding process of plastic injection mold steel. Materials and Manufacturing Processes. 2016;31(9):1192-1200.

10 Menezes CM, Bogoni N Jr, Barrirero J, Aboulfadl H, Mücklich F, Figueroa CA. Influence of the surface chemistrystructure relationship on the nanoscale friction of nitrided and post-oxidized iron. Surface and Coatings Technology. 2016;308:220-225.

11 Pérez M, Belzunce FJ. A comparative study of salt-bath nitrocarburizing and gas nitriding followed by postoxidation used as surface treatments of H13 hot forging dies. Surface and Coatings Technology. 2016;305:146-157.

12 Mahboubi F, Fattah M. Duplex treatment of plasma nitriding and plasma oxidation of plain carbon steel. Vacuum. 2005;79(1-2):1-6. 
13 Freislebem M, Menezes CM, Cemin F, Costi FB, Ferreira PA, Aguzzoli C, et al. Influence of the chemical surface structure on the nanoscale friction in plasma nitrided and post-oxidized ferrous alloy. Applied Physics Letters. 2014;105(11):111603.

14 Bhushan B. Modern tribology handbook. 2. Materials, coatings, and industrial applications. Boca Raton: CRC Press; 2001.

$15 \mathrm{Wu}$ T, Wang J, Peng Y, Zhang Y. Description of wear debris from on-line ferrograph images by their statistical color. Tribology Transactions. 2012;55(5):606-614. http://dx.doi.org/10.1080/10402004.2012.686086.

16 Zum Gahr KH. Microstructure and wear of materials. Amsterdam: Elsevier; 1987.

17 Kruschov MM. Resistance of metals to wear by abrasion, as related to hardness. In: Proceedings of the Conference on Lubrication and Wear; 1957; London. London: IME; 1957.

18 American Society for Testing \& Materials. ASTM E92-16: standard test methods for vickers hardness and knoop hardness of metallic materials. West Conshohocken: ASTM ; 2016.

19 International Organization for Standardization. ISO BS EN 286-1:2010: Geometrical Product Specifications (GPS): ISO code system for tolerances on linear sizes. Geneve: ISO; 2010.

20 Karamış MB, Yıldızlı K, Çarkıt Aydın G. Sliding/rolling wear performance of plasma nitrided H11 hot working steel. Tribology International. 2012;51:18-24. http://dx.doi.org/10.1016/j.triboint.2012.02.005.

21 Cruz MR, Nachez L, Gomez BJ, Nosei L, Feugeas JN, Staia MH. Ion nitrided AISI H13 tool steel part Imicrostructural aspects. Surface Engineering. 2006;22(5):359-366. http://dx.doi.org/10.1179/174329406X126663.

22 Borgioli F, Galvanetto E, Fossati A, Bacci T. Glow-discharge nitriding and post-oxidizing treatments of AISI H11 steel. Surface and Coatings Technology. 2003;162(1):61-66. http://dx.doi.org/10.1016/S0257-8972(02)00574-1.

23 Panfil D, Kulka M, Wach P, Michalski J, Przestacki D. Nanomechanical properties of iron nitrides produced on 42CrMo4 steel by controlled gas nitriding and laser heat treatment. Journal of Alloys and Compounds. 2017;706:6375. http://dx.doi.org/10.1016/j.jallcom.2017.02.220.

Received: 9 June 2019

Accepted: 6 July 2020 